\title{
Nematode Feeding Types in Different Soil Habitats and Subsequent Study in Maize Field
}

\author{
Mohammod Hossain ${ }^{1, *}$, Maurice Moens ${ }^{2}$, Nancy De Sutter ${ }^{3}$ \\ ${ }^{1}$ Bangladesh Rice Research Institute, Bangladesh and Ghent University, Belgium \\ ${ }^{2}$ Faculty of Sciences and Bioscience Engineering, University of Ghent, Belgium \\ ${ }^{3}$ Institute for Agricultural and Fisheries Research (ILVO), Belgium
}

Copyright $\bigcirc 2016$ by authors, all rights reserved. Authors agree that this article remains permanently open access under the terms of the Creative Commons Attribution License 4.0 International License

\begin{abstract}
Three experiments were conducted to find out the feeding type and age structure of nematodes in different soil habitats; to know the efficiency of different extraction techniques of nematodes and to observe the hatching behavior of Meloidogyne juvenile in a Baermann device. Bacterivore, Omnivore, Predator, Fungivore and Plant Parasitic nematodes were recorded in the soil of flower, vegetable, moss, grass, and corn and compost habitats. Bacterivore was the highest feeder $(67.5 \%)$ in the soil habitats. In comparison of nematode extraction methods, Seinhorst method extracted more cysts (188), but less juvenile (34) and eggs (18) from cysts than stirring $(145,87$ and 50, respectively) while AZC was found superior (936) over Cobb method (204) in extracting nematodes. The AZC method also extracted huge juvenile number from roots which was higher than Baermann funnel method. In Baermann funnel, juvenile hatched more in favorable condition than unfavorable condition which led to an increasing and decreasing pattern of hatching.
\end{abstract}

Keywords Nematode Trophic Groups, Extraction Methods, Soil, Plant Root, Hatching

\section{Introduction}

Accurate assessment of all members of the nematode community is essential for obtaining a clear impression of community composition. Nematodes can be free-living or parasitic to plant and animal. Substrates such as litter, moss, or compost often contain high numbers of non-parasitic (Saprophagous) nematodes of plant. For estimation of nematode feeding types and calculation of their contribution to energy and nutrient uses in soil ecosystems, it is necessary to obtain a reliable quantification of nematode numbers in soil. This also holds for population studies that need reliable estimates of age-structure and sex-ratio [12, 26].

Plant parasitic nematodes cause significant economic reduction to crops. Annually, about $54 \%$ of the soybean yield reduction was caused by soybean cyst nematode in the US which is equivalent to167 $\times 10^{7} \$$ [29]. Before giving appropriate recommendations, the specific types and numbers of nematodes present in the field must be determined $[20,28]$.

While a wide variety of methods for extracting nematodes from soil are available, all are imperfect and have various degrees of inefficiency $[2,17,22]$. As a result, many laboratories choose a method that gives the most efficient and consistent results for local conditions and nematodes of particular concern (often common plant parasites) or interest [21]. Most methods use a combination of different principles [26]. There are major differences in terms of extraction efficiency, size of the sample that can be handled, and costs $[2,21]$.

It is necessary to know the different types of nematode in certain habitats to grow better crops. Considering the above fact, an experiment was conducted to identify different feeding types and age structures of nematodes in different soil habitats. A secondary objective was to determine hatching behavior of Meloidogyne juvenile in a Baermann device. At the same time another experiment for maize crop field was conducted with a goal to determine which class of extraction method is more effective in assessing nematode community composition.

\section{Materials and Methods}

Three experiments were conducted at University Gent, Belgium to meet the objectives. Those were: $i$ ) feeding type and age structure of nematodes in different soil habitats; ii) study on the efficiency of different extraction techniques of nematodes and iii) hatching behavior of Meloidogyne juvenile in a Baermann device.

\subsection{Collection of Soil and Plant Sample}

Soil from six different habitats namely vegetables, moss, 
grass, flowers, corn and compost were collected from and near the Botanical garden, University of Gent, Belgium to find out different feeding types and age structures of nematodes (in the experiment 1). Soil and plant root were collected from maize field to study efficiency of different extraction techniques of nematodes (in the experiment 2). Knotted-root of Tomato was collected to know the hatching behavior of Meloidogyne juvenile (in the experiment 3).

Six replicate cores, each consisting of six combined cores (2.52 cm x $20 \mathrm{~cm}$ deep) were taken from within a $5 \times 5 \mathrm{~m}$ area of each sampled vegetative site. Sampling depth was 6 inches. Collected samples were placed in separate labeled bags. Roots of plants were also kept in separate bags. All bags containing nematode samples were stored at $10^{\circ} \mathrm{C}$ for overnight.

\subsection{Extraction of Nematode}

The modified Baermann Funnel extraction method [1] was used to observe different feeding types and age structures of nematodes in different soil habitats. About 50 nematodes were picked up randomly, mounted on slides and observed under microscope. Age structures were classified based on gender and as juveniles if genital structures were not visible (in the experiment 1).

Cobb's decanting and sieving [9] method (300ml soil used) and Automatic Zonal Centrifugal (AZC) floatation [16] method (with $200 \mathrm{ml}$ soil) were used to extract free-living nematodes from soil. Cysts were extracted from soil by stirring [23] (300g dry soil used) and Seinhorst [27] method (with 500g wet soil). Amount of soil samples were converted by using following formulae to homogenize the data for comparing different extraction methods [28].

$$
\begin{aligned}
& \text { Nematodes }_{\mathrm{vol}}=\frac{(V 2 X n 1)}{V 1}\left(\frac{100}{V 3}\right) \text { nematodes per } 100 \mathrm{ml} \text { sample } \ldots \ldots \ldots \ldots(1) \\
& \text { Nematodes }_{\mathrm{ww}}=\frac{(V 2 X n 1)}{V 1}(100 / \mathrm{W}) \quad \text { nematodes per } 100 \mathrm{~g} \text { wet sample......... }
\end{aligned}
$$

Where, $\mathrm{n} 1=$ number of nematodes in $\mathrm{v} 1$

$\mathrm{v} 1=$ volume $(\mathrm{ml})$ of the counted suspension obtained from $\mathrm{v} 2$

$\mathrm{v} 2=$ volume $(\mathrm{ml})$ of the extracted sample total suspension

$\mathrm{v} 3=$ volume $(\mathrm{ml})$ of the sample

$\mathrm{W}=$ weight $(\mathrm{g})$ of the sample

$$
\mathrm{ww}=\text { Wet weight and vol }=\text { Volume }
$$

The AZC floatation method (with $5 \mathrm{~g}$ maize root) was used for extraction of nematodes from maize roots (in the experiment 2). Six locations (samples) were selected from the field, and one plant in each location was dug out. Seminal roots from vegetative stage of plants were collected. Dried maize roots $(5 \mathrm{~g})$ were macerated and the nematodes were extracted through centrifugation.

In hatching pattern (experiment 3), Baermann method was used to extract motile juveniles from roots of tomato plants that had been inoculated with Meloidogyne species. The plant roots were chopped in 1-2 $\mathrm{cm}$ pieces and $5 \mathrm{~g}$ were taken and placed in filter papers on Baermann funnel under laboratory condition. Fresh tap water was added to increase favorable condition in the system. Hatching behavior of Meloidogyne juvenile was observed. Data on number of Meloidogyne juveniles were recorded in every two days interval and continued up to 12 counts.

\subsection{Data Analysis}

Based on literature on feeding habits [30], nematodes were assigned to five trophic groups: Bacterivore, Fungivore, Omnivore, Predator and Plant Parasitic. Percent composition by trophic group was calculated for each sample. Comparisons between extraction methods were made by analysis of variance (ANOVA) using MSTAT-C software [13]. Unless otherwise stated, all differences referred to in the text were significant, $\mathrm{P}=0.05$. Nematode data on the number of juveniles of Meloidogyne sp. in hatching pattern was taken at every 2-day interval.

\section{Results}

Feeding type and age structure of nematodes in different soil habitats

Analysis of the feeding groups was completed for all six of the cores taken from each of the vegetation types and the mean \% compositions calculated (table 1). Five feeding types viz. Bacterivore, Omnivore, Predator, Fungivore and Plant Parasitic nematode were recorded in the soil of flower, vegetable, moss, grass, corn and compost. In the flower garden, higher number of nematodes was recorded as Bacterivore (67.5\%) followed by omnivore (13.8\%), predator $(12.2 \%)$, and plant parasitic (4.9\%) whereas lower number of feeding type of nematodes was Fungivore (1.6\%) (Table1). Similar trend was observed in the corn and Moss fields except that Fungivore was higher than Plant Parasitic nematodes in the Moss habitat. In the vegetable garden, higher number of nematodes was Bacterivore (49.4\%) which was followed by Plant Parasitic (25.5\%), Omnivore (13.3\%), Fungivore $(8.1 \%)$ and predator $(3.3 \%)$. Lower number of nematodes was recorded as Predator $(4.8 \%)$ in the grass habitat which was precedingly followed by Omnivore (8.8\%), Fungivore (14.3\%), and Plant Parasitic (34.8\%) whereas Bacterivore was the highest (37.4\%) feeder in the nematode community. The compost which has a large amount of organic matter consisted of large number (50.2\%) of Bacterivore. Second highest number of nematodes in compost was predator $(25.3 \%)$ and it was followed by Fungivore (13.1\%), omnivore $(8.7 \%)$ and plant parasitic (2.8\%) (Table1). Figure1 indicated that presence of Bacterivore was dominant $(48 \%)$ in the observed soil habitats over Omnivore (17), Predator (15), Plant Parasitic (13) and Fungivore (8). 
Table 1. Summary table (\%) of feeding types in six different soil types

\begin{tabular}{c|c|c|c|c|c|c}
\hline Feeding Types & Flowers & Vegetable & Moss & Grass & Corn & Compost \\
\hline Bacterivore & 67.5 & 49.8 & 32.2 & 37.4 & 48.2 & 50.2 \\
Omnivore & 13.8 & 13.3 & 31.9 & 8.8 & 23.8 & 8.7 \\
Predator & 12.2 & 3.3 & 27.3 & 4.8 & 17.0 & 25.3 \\
Fungivore & 1.6 & 8.1 & 7.6 & 14.3 & 4.6 & 13.1 \\
Plant Parasitic & 4.9 & 25.5 & 1.0 & 34.8 & 6.4 & 2.8 \\
\hline SE & 4.6 & 3.2 & 2.5 & 2.6 & 3.0 & 3.2 \\
\hline
\end{tabular}

There were four age structures namely juvenile, non gravid female (-egg), gravid female (+egg) and male in nematode trophic group under six soil habitats (Figure2). The presence of juveniles was dominant over the other age structures. About $61.3 \%$ of the nematode was juvenile whereas non gravid females (-egg), gravid females (+egg) and males were $21.0 \%, 9.0 \%$ and $8.7 \%$, respectively.

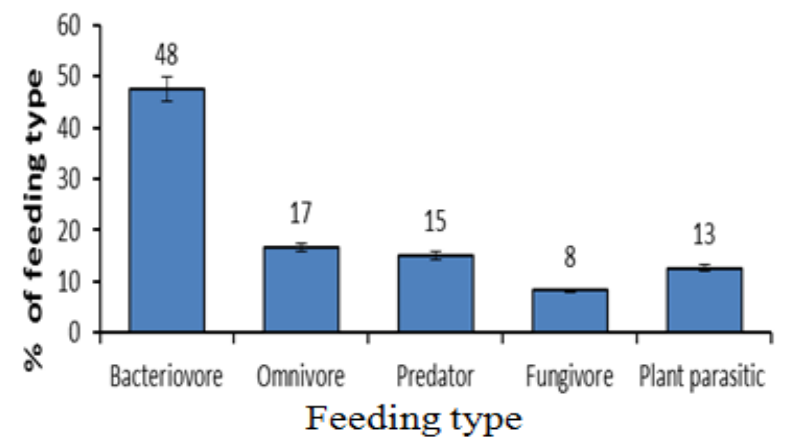

Figure 1. Comparison of tropic level (feeding type) irrespective of soil type

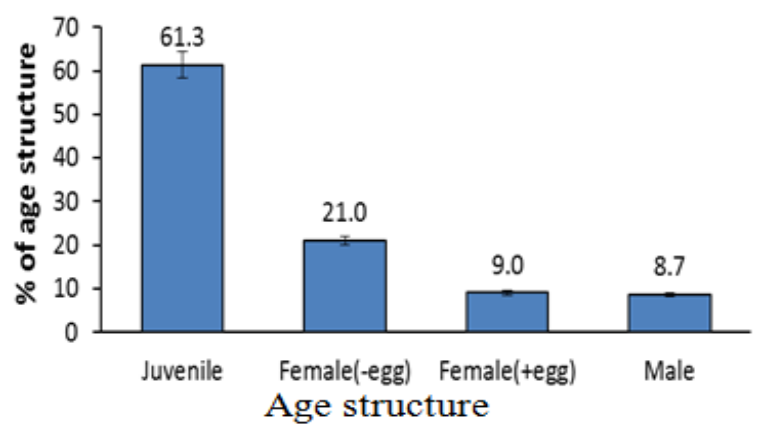

Figure 2. Comparison of age structure irrespective of feeding and soil type

\subsection{Comparison of Different Extraction Method of Nematode}

\subsubsection{Comparison of stirring and Seinhorst method in extraction of cysts from soil}

Two methods were employed to extract cysts form the soil. These methods were Seinhorst and stirring method. Both methods use the principle that nematodes cysts float on water. Dry cysts contain air bubble. Significantly higher number of cysts was recorded in Seinhorst method (188) compare to stirring method (145). Juveniles and eggs from selected 10 cysts were counted. Eggs were broken using fine needle. Number of Juveniles (J2) in 10 cysts in stirring method was 87 which was about two and half times higher than that of Seinhorst method (34). Eggs in those cysts were also significantly higher in stirring method (50) than that of Seinhorst method (18) (Figure 3).

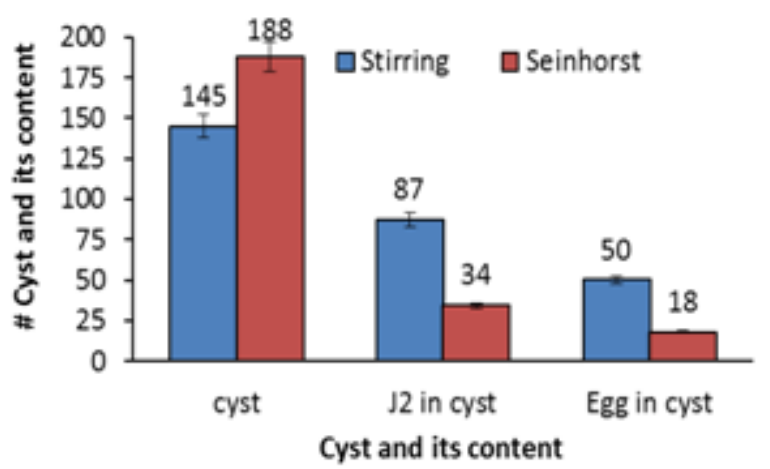

Figure 3. Number of cysts and its contents in Cobb and Seinhorst method

\subsubsection{Comparison of Cobb's and AZC methods in extraction of vermiform nematodes from soil}

These two methods use the principle of differential sizes and weight of the nematodes. Nematodes larger than the sieve sizes are retained while all particles smaller than the sieve size pass through.

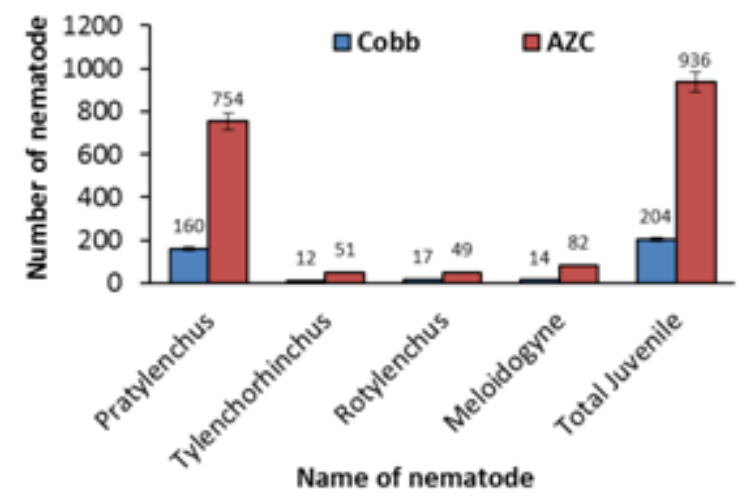

Figure 4. Extraction of nematodes by Cobb and Seinhorst method

The results were presented in Figure 4 (also Appendix 1).Four types of nematode viz. Pratylenchus sp., Tylenchorhynchus sp., Rotylenchus sp. and Meloidogyne sp. were recorded from the tested soil sample. Significantly higher number of those nematodes was observed in AZC floatation method compare to Cobb's decanting and sieving 
method. In Cobb's method, the number of Pratylenchus sp., Tylenchorhynchus sp., Rotylenchus sp. and Meloidogyne sp were $160,12,17$ and 14 respectively whereas in AZC floatation method the number of those nematodes were 754 , 51, 49 and 82, respectively. Irrespective of nematode genus number of juvenile was significantly higher in AZC (936) over Cobb's method (204) (Figure 4).

\subsubsection{Extraction of nematodes from root}

Four types of nematodes viz. Pratylenchus sp., Tylenchorhynchus, Rotylenchus and Meloidogyne were recorded form maize root (Table 2; Appendix 2). An average number of 1005 Pratylenchus sp. was extracted from per $5 \mathrm{~g}$ maize root under AZC floatation method. A few numbers of Tylenchorhynchus, Rotylenchus and Meloidogyne were also observed. This was not statistically compared with Baermann funnel because of different types of root.

\subsection{Hatching Behavior of Meloidogyne Juvenile}

The Baermann method was used to extract motile juveniles from roots of tomato plants that had been inoculated with Meloidogyne species. Figure 5 represented the hatching pattern of Meloidogyne juvenile. Out of 12 counting, in the first counting, juvenile of Meloidogyne sp. was lower (498) but in the second counting it was increased (1083). Number of juvenile was decreased in the $3^{\text {rd }}$ counting (822) and reached at the highest in the $4^{\text {th }}$ counting (1825). An alternate increasing and decreasing trends of number of juvenile was observed up to the seventh counting. After that the number of juveniles was decreased gradually and reached at minimum (315) in the $10^{\text {th }}$ counting. There was no juvenile recorded in the $11^{\text {th }}$ and $12^{\text {th }}$ counting.

\section{Discussion}

The result of experiment 1 indicated that the tested soils were mostly infected by free-living nematodes. Few plant parasitic nematodes were recorded from those soils (Table 1 and Figure 1).The soil of botanical garden and also compost was rich of organic matter which might be responsible for having decomposing bacteria in the soil and ultimately led to the highly presence of Bacterivore nematodes. Other organisms like fungi also grow in organic matter riched soil. These might be the cause of higher presence of Omnivore, Predator and Fungivore. Grass, vegetable and corn were good host for plant parasitic nematodes. The composition of soil, season, soil moisture, type of crop, cropping pattern etc. might be responsible for low presence of plant parasitic nematodes. McSorley and Frederick [22] described five trophic group of nematode in soil habitat such as Bacterivore, Omnivore, Predator, Fungivore and herbivore. They recorded Bacterivore as the highest number of nematode in the community. They extracted a large number of these nematodes by Baermann method. Similar results were presented by others [17, 24, 30]. Ferris [12] observed higher number of juvenile among different age structures in nematode. Their results supported the present findings.

Table 2. Number of nematodes from roots using AZC and Baermann funnel methods

\begin{tabular}{c|c|c|c|c}
\hline $\begin{array}{c}\text { Extraction } \\
\text { Method }\end{array}$ & Pratylenchus sp. & Tylenchorhynchus sp. & Rotylenchus sp. & Meloidogyne sp. \\
\hline AZC & 1005 & 7 & 7 & 18 \\
Baermann funnel & 0 & 0 & 0 & 1825 \\
\hline
\end{tabular}

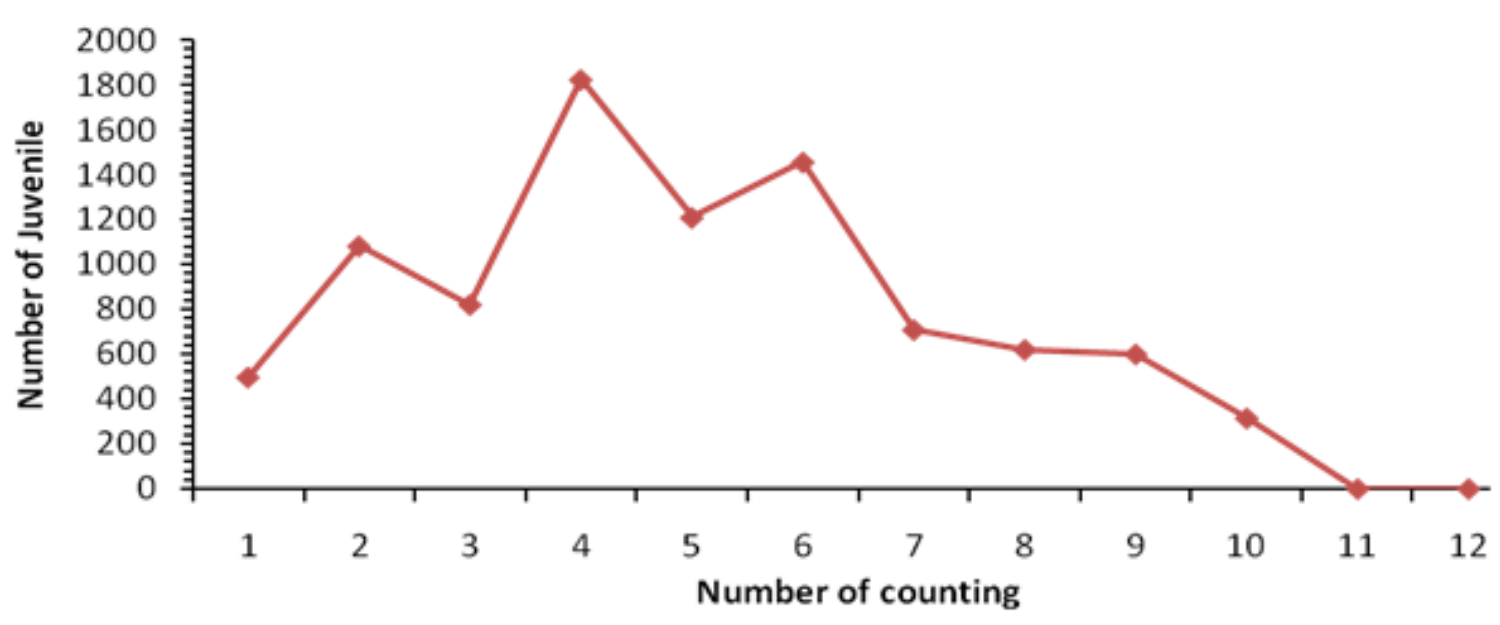

Figure 5. Hatching behavior of juvenile of Meloidogyne sp. under Baermann funnel 
Stirring and Seinhorst methods were designed on the principle of floatation of cysts on water. Air dried soil was used in stirring method where old cysts were also dried and having air bubble, dried cysts floated on water. But in that case, younger cysts those were not properly dried might not be floated on water hence they might not be recovered. This might be the reason of getting lower number of cysts in stirring method compared to Seinhorst method (Figure 3). But this method was easy and quick. On the other hand, soil didn't need to be dried in Seinhorst method. This method recovered young cysts which normally didn't float on water. The principles of Seinhorst method allowed maximum extraction of cysts from soil hence the efficiency was found higher than stirring method. Number of eggs and juveniles in cysts were not higher in Seinhorst method over stirring method. Only the old cysts were collected by stirring method while Seinhorst method recovered younger and older cysts, even empty cysts which might affect the number of juveniles and eggs in cysts. Been et. al. [4] used a scaled-up Seinhorst elutriator for extraction of cyst nematodes from soil and found more efficient in extracting cysts compare to stirring method. Van Bezooijen [28] also described the similar observation. The present data were supported by their results. Though Seinhorst method required more water, spent more time and costly compare to stirring method, it could be fit for huge amount (up to $1 \mathrm{~kg}$ ) of soil sample. Seinhorst apparatus could be bought by group of farmers to minimize cost.

Four types of vermiform nematodes were identified (Figure 4). Though Pratylenchus is essentially parasite of root cortex, it could be found in soil also. Rotylenchus and Tylenchorhynchus are ectoparasites and found in soil. Meloidogyne also endoparasitic but males come out in the soil from roots. This might be the reason of getting those nematodes in soil. But presence of Pratylenchus was the maximum in number. Sample was collected from maize field. Maize might not be good host for Tylenchorhynchus, Rotylenchus and Meloidogyne but good host for Pratylenchus which might be the cause of having more Pratylenchus in sample. The results of the present study are in accordance with the results of some other researchers $[10$, $11,7,15]$. Total number of nematodes was higher in AZC method. In AZC method, organic portion (root) of the soil sample was blended and mixed with mineral portion (soil) which was not done in Cobb's method. So Pratylenchus from roots and soil mixed together. This might be the cause of getting more Pratylenchus in the sample which ultimately increased the total number of juveniles in AZC method. This method also extracted immotile nematodes. Similar result was also recorded by Sarah and Boisseau [25] where the centrifugal-flotation technique allowed all nematode species and life stages to be separated from root debris and residual soil particles. Similar results were observed by other scientists [19, 8]. Another researcher [6] also found centrifugation to be seven times as efficient as a modified sieving and decanting technique for recovering large nematode species, species with a special way of movement, and species with a rough cuticle. The present study was supported by their studies.

Cobb's method was designed on the principle of differences in shape, size and weight of nematodes and their motility. It is easy to use and can avoid sophisticated apparatus. But it is laborious and can't provide accurate result in quantitative measurement. On the other hand, the AZC method was designed on the principle of differences in density of suspension and nematodes. Moens and Viaene [23] observed that alive or preserved nematode and even cysts could be extracted by this method. This method is relatively faster and can obtain clear nematode suspension. But this method alter the shape and influence the vitality of nematodes hence it limits the pathogenicity test or identification. From our results, it is clearly observed that the efficiency of AZC method in extracting vermiform nematodes is superior compare to Cobb's method. McSorley and Frederick [22] also reported the superiority of centrifugation method in extracting vermiform nematodes which was similar with our results. The huge cost of AZC apparatus could be minimized by community based farming where this method could be used by many farmers. This apparatus also could be organized institutionally where soil samples could be sent and analyzed by simple cost.

Nematodes are host-specific. Pratylenchus are parasitic nematodes for maize plants. They are endoparasitic and are mostly embedded in the plant roots. They make tunnel in the roots cortex. Presence of huge number of Pratylenchus sp. in root indicates the maize as its host (Table 2). A little presence of Tylenchorhynchu sp., Rootlenchus sp. and Meloidogyne sp. is attributed by the fact that maize is not the specific hosts for these nematodes. A similar result was also described by other researcher [18]. Also Tylenchorhynchus and Rotylenchus are large worms that move slowly. The short time allowed for experiment could not give the nematode time to move outside the roots. Again these two nematodes could have been destroyed through maceration. Batista da Silva [3] observed that Baermann funnel was not efficient for extraction of Pratylenchus from root in their experiment. Meloidogyne are specific in tomato plants hence a large number of that nematode ware recorded from tomato root. Results of the critical comparisons between Baermann and centrifugation methods were not so consistent. Baermann incubation was clearly superior for some genus while centrifugation was the better method for others (Table 2 ). Present data and results from previous work $[14,2]$ confirm the advantage of centrifugation over Baermann incubation in the recovery of sluggish plant-parasitic.

Collected tomato roots were heavily knotted and there were a lot of matured egg masses. Juvenile from those matured egg masses were hatched in presence of water in Baermann funnel which might be the cause to attribute a high number of juvenile in $2^{\text {nd }}$ counting (Figure 5). Baermann funnel method has a disadvantage of poor oxygenation. Carbon dioxide also increased due to respiration of nematodes which produced mild carbonic acid. These might affect hatching of juvenile hence reduced number of juvenile 
was attributed in third counting. Bearmann method recovers only the active motile nematodes. Later fresh tap water was added which increased oxygen and decreased carbonic acid in the system. This might increase juvenile in $4^{\text {th }}$ counting allowing favorable condition for hatching. Similar trends were recorded up to later counting. Batista da Silva [3] reported that poor oxygenation in Bearmann method hampered nematode hatching. They also observed an alternate increasing and decreasing of nematode counting in this method. Behn [5] also recorded the similar results. Their results were in accordance with the present study.

\section{Conclusions}

1. Bacterivore, Omnivore, Predator, Fungivore and Plant Parasitic nematode were recorded in the soil of flower, vegetable, moss, grass, and corn and compost field. Bacterivore was the highest feeder in the soil habitats.

2. Efficiency in estimating population density of nematodes in a certain area is affected by sampling, handling of sample, extracting and counting nematodes of the technician. All the extraction techniques have their disadvantages with their advantages. None of them can be used as efficiently as 100 percent. Depending on the purpose or type of the study, method can be selected for extraction. However, selection of a technique depends on their availability and cost.

3. In Baermann funnel, juvenile hatched more in favorable condition than unfavorable condition. An increasing and decreasing pattern of hatching of nematode was recorded.

\section{Acknowledgements}

This work was supported by the scholarship of Erasmus Mundus. The authors thank all the members and students of research group during his study for their cooperation. We express our appreciation to Nic smol, Inge Dehennin and other members of Gent University for their assistance.

\section{Appendices}

Appendix 1. Homogenize data on nematodes from soil (by using formula 1)

\begin{tabular}{|c|c|c|c|c|c|c|c|c|c|c|c|}
\hline \multirow{2}{*}{$\begin{array}{l}\text { Extraction } \\
\text { Method }\end{array}$} & \multirow{2}{*}{$\begin{array}{c}\text { Volume } \\
(\mathrm{ml}) \text { of } \\
\text { Sample }=\mathrm{v} 3\end{array}$} & \multirow{2}{*}{$\begin{array}{l}\text { Volume }(\mathrm{ml}) \text { of } \\
\text { extracted } \\
\text { sample total } \\
\text { suspension } \\
=\mathrm{v} 2\end{array}$} & \multirow{2}{*}{$\begin{array}{l}\text { Volume }(\mathrm{ml}) \text { of } \\
\text { counted } \\
\text { suspension } \\
\text { obtained from v2 } \\
=\mathrm{v} 1\end{array}$} & \multicolumn{4}{|c|}{$\begin{array}{l}\text { Number of nematodes in v1 } \\
=\mathrm{n} 1\end{array}$} & \multicolumn{4}{|c|}{$\begin{array}{c}\text { Number of nematodes per } \\
100 \mathrm{ml} \text { sample }\end{array}$} \\
\hline & & & & Pra & Rot & Tyl & $\mathrm{Mel}$ & Pra & Rot & $T y l$ & $\mathrm{Mel}$ \\
\hline $\mathrm{AZC}$ & 200 & 500 & 10 & 30.2 & 2.0 & 2.0 & 3.3 & 754 & 51 & 49 & 82 \\
\hline COBBS & 300 & 80 & 10 & 60.0 & 4.5 & 6.4 & 5.3 & 160 & 12 & 17 & 14 \\
\hline
\end{tabular}

Pra=Pratylenchus; Rot=Rotylenchus; $T y l=$ Tylenchorhynchus; Mel=Meloidogyne

Appendix 2. Homogenize data on nematodes from roots (by using formula 2)

\begin{tabular}{|c|c|c|c|c|c|c|c|c|c|c|c|}
\hline \multirow{2}{*}{$\begin{array}{c}\text { Extraction } \\
\text { Method }\end{array}$} & \multirow{2}{*}{$\begin{array}{c}\text { Weight } \\
(\mathrm{g}) \text { of } \\
\text { Sample }=\mathrm{W}\end{array}$} & \multirow{2}{*}{$\begin{array}{l}\text { Volume }(\mathrm{ml}) \text { of } \\
\text { extracted } \\
\text { sample total } \\
\text { suspension = v2 }\end{array}$} & \multirow{2}{*}{$\begin{array}{c}\text { Volume }(\mathrm{ml}) \text { of } \\
\text { counted } \\
\text { suspension obtained } \\
\text { from } \mathrm{v} 2=\mathrm{v} 1\end{array}$} & \multicolumn{4}{|c|}{$\begin{array}{l}\text { Average number of nematodes } \\
\text { in } \mathrm{v} 1=\mathrm{n} 1\end{array}$} & \multicolumn{4}{|c|}{$\begin{array}{c}\text { Number of nematodes per } \\
100 \mathrm{~g} \text { sample }\end{array}$} \\
\hline & & & & Pra & Rot & $T y l$ & $\mathrm{Mel}$ & Pra & Rot & $T y l$ & $\mathrm{Mel}$ \\
\hline $\mathrm{AZC}$ & 5 & 80 & 10 & 6.28 & 0.04 & 0.04 & 0.11 & 1005 & 7 & 7 & 18 \\
\hline Bearmann & 5 & 100 & 10 & 0.00 & 0.00 & 0.00 & 9.13 & 0 & 0 & 0 & 1825 \\
\hline
\end{tabular}

Pra=Pratylenchus $;$ Rot=Rotylenchus $; T y l=$ Tylenchorhynchus $;$ Mel=Meloidogyne 


\section{REFERENCES}

[1] Baermann, G. (1917). Eine einfache Methode zur Auffindung von Ankylostomum (nematoden) Larven in Erdproben. Geneesk. Tijdschr. Ned-Indië.57: 131-137.

[2] Barker, K.R. and Campbell, C.L. (1981). Sampling nematode populations. In: Zuckerman, B.M. and Rohde, R.A. (Eds.), Plant Parasitic Nematodes, vol. 3. Academic Press, New York, pp. 451-474.

[3] Batista da Silva, M. (2013). Studies on extraction and control of plant-parasitic nematodes on corn. Graduate Theses and Dissertations. Paper 13157. http://lib.dr.iastate.edu/etd

[4] Been, T. H., Bekkum van J. P., Beers van, Thea, G. and Beniers, A. (2007). A scaled-up Seinhorst elutriator for extraction of cyst nematodes from soil. Nematology. 9 (3): 431-435.

[5] Behn, J. L. (2012). Comparison of Methods and Corn Root Types for Efficient Extraction of Endoparasitic Nematodes. Theses, Dissertations, and Student Research in Agronomy and Horticulture. University of Nebraska-Lincoln. Paper 48.

[6] Boag, B. and Orton Williams, K.J. (1976). The Criconematidae of the British Isles. Annals of Applied Biology 84, 361-369.

[7] Castillo, P. and Vovlas, N. (2007). Pratylenchus (Nematoda: Pratylenchidae): Diagnosis, biology, pathogenicity and management. Brill Academic Publishers, Leiden, Netherlands. 529 pp.

[8] Caveness, F. E. and Jensen, H. J. (1955). Modification of the centrifugal flotation technique for the isolation and concentration of nematodes and their eggs from soil and plant tissue. Proceedings of the Helminthological Society of Washington 22:87-89.

[9] Cobb, N.A. (1918). Estimating the nema population of the soil. Agric. Tech. Circ. Bur. Pl. Ind. U.S. Dep. Agric. 1. 48

[10] De Waele, D. and Elsen, A. (2002). Migratory endoparasites: Pratylenchus and Radopholus species. Pp. 175-206. In: Starr, J. L., Cook, R. and Bridge, J. (eds.) Plant Resistance to Parasitic Nematodes. CABI Publishing, Wallingford, Oxon, UK. pp. 258.

[11] Duncan, L. W. and Moens, M. (2006). Migratory endoparasitic nematodes. Pp. 123-152. In: Perry, R. N. and Moens, M. (eds.). Plant Nematology. CAB International, Oxfordshire, UK. 447 pp.

[12] Ferris, H. (1987). Extraction efficiencies and population estimation. In: Veech, J.A. and Dickson, D.W. (Eds.), Vistas on Nematology. Society of Nematologists, Hyattsville, MD, pp. 59-63.

[13] Freed, R., Eisensmith, S.P., Goetz, S., Reicosky, D., Smail, V.W. and Wohlberg, P. (1991). User's Guide to MSTAT-C. Michigan State University, East Lansing, MI.

[14] Harrison, J.M. and Green, C.D. (1976). Comparison of centrifugal and other methods for standardization of extraction of nematodes from soil. Ann. Appl. Biol. 82, 299-308.

[15] Hassan, J., Chishti, M. Z., Rasheed, M., Ahmad, .I., Ahmad, F. and Lone, B. A. (2009). Nematodes associated with Zea mays and their control through organic soil amendments. International Journal of Plant Production 3:71-75.

[16] Hendrickx, G. (1995). An automatic apparatus for extracting free-living nematodes stages from soil. Nematologica. 41: 308

[17] Hooper, D.J. (1986). Extraction of free-living stages from soil. In: Southey, J.F. (Ed.), Laboratory Methods for Work with Plant and Soil Nematodes. Her Majesty's Stationery Office, London, pp. 5-30. http://digitalcommons.unl.edu/agronhortdiss/48

[18] Lavallee, W. H. and Rohde, R. A. (1962). Attractiveness of plant roots to Pratylenchus penetrans (Cobb). Nematologica 8:252-260.

[19] MacGuidwin, A. E. (1989). Distribution of Pratylenchus scribneri between root and soil habitats. Journal of Nematology 21:409-415.

[20] Mai, W. F. (1985). Plant parasitic nematodes: their threat to crop production (In An advanced treaties on Meloidogyne) Vol. 1, Biology and control. Edited by Sasser, J. N. and Carter, C. C. North Carolina State University. 11-17.

[21] McSorley, R. (1998). Population dynamics. In: Barker, K.R., Pederson, G.A. and Windham, G.L. (Eds.), Plant and Nematode Interactions. American Society of Agronomy, Crop Science Society of America, Soil Science Society of America, Madison, WI, pp. 109-133.

[22] McSorley R. and Frederick J.J. (2004). Effect of extraction method on perceived composition of the soil nematode community. Applied Soil Ecology 27: 55-63.

[23] Moens M. and Viaene, N. (2003). General techniques used in nematology. International Nematology Course. University of Ghent, Gent, Belgium.

[24] Porazinska, D. L., Duncan, L. W., McSorley, R. and Graham, J.H. (1999). Nematode communities as indicators of status and processes of a soil ecosystem influenced by agricultural management practices. Appl. Soil Ecol. 13, 69-86.

[25] Sarah J.L. and Boisseau, M. (2008). Nematode extraction from banana roots by the centrifugal-flotation technique. Fruits. 63: 249-251.

[26] Schouten, A.J. and Arp, K.K.M. (1991). A comparative study on the efficiency of extraction methods for nematodes from different forest litters. Pedobiologia 35, 393-400.

[27] Seinhorst, J. W. (1964). Methods for the extraction of Heterodera cysts from not previously dried soil. Nematologica. 10: 87-94.

[28] Van Bezooijen. J. (2006). Methods and techniques for nematology. Electronic PDF revised version. Wageningen, December 2006.

[29] Wrather, J.A., Stienstra, W. and Koenning, S.R. (2001b). Soybean disease loss estimates for the United States from 1996 to 1998. Can. J. Plant Pathol. 23:122-131.

[30] Yeates, G. W., Bongers, T., de Goede, R. G. M., Freckman, D. W. and Georgieva, S. (1993). Feeding habits in soil nematode families and genera-an outline for soil ecologists. J. Nematol. 25, 315-331. 